\title{
The Relationship between Range of Motion and Function of Upper Extremity in Obstetric Brachial Plexus Palsy Patients Treated with Tendon Transfer
}

\author{
Zeynep Hosbay, ${ }^{1,}$ Muberra Tanrıverdi, ${ }^{2}$ Ela Tarakci, ${ }^{2}$ Atakan Aydın, ${ }^{3}$ and Arzu Razak Ozdincler ${ }^{2}$ \\ ${ }^{1}$ Department of Physiotherapy and Rehabilitation, Faculty of Health Sciences, Bezmialem Vakif University, Istanbul, Turkey \\ ${ }^{2}$ Department of Plastic Surgery, Istanbul Medical Faculty, Istanbul University, Istanbul, Turkey \\ ${ }^{3}$ Department of Physiotherapy and Rehabilitation, Faculty of Health Sciences, Istanbul University, Istanbul, Turkey \\ "Corresponding author: Zeynep Hosbay, PhD, PT, Vatan Caddesi, 34093, Fatih, Istanbul, Turkey. Tel: +90-5055034279, Fax: +90-2124531870, E-mail: zeynephosbay@gmail.com
}

Received 2016 March 20; Revised 2017 June 12; Accepted 2017 October 02.

\begin{abstract}
Obstetric brachial plexus palsy (OBPP) refers to upper limb paralysis secondary to a sustained traction or compression injury to the brachial plexus during birth. The reported incidence in developed countries is 2 per 1000 live births. The assessment and planning of appropriate treatment is important in the early stages of OBPP. The aim of our study was to examine the relationship between the range of motion and upper extremity function of the shoulder in patients with OBPP who were treated by tendon transfer. This study included 48 patients who had shoulder tendon transfer at least 6 months ago in Istanbul Medical Faculty, Department of Plastic and Reconstructive Surgery, Department of Surgery of the Hand. Range of motion measurements were performed using a universal goniometer and the modified mallet classification was used to categorize global shoulder function. Pediatric evaluation of disability inventory (PEDI) and Canadian occupational performance measure (COPM) were used to evaluate functional ability, activity and participation. When examining relationships between range of motion and functional scores, there was a statistically significant relationship between COPMP score and external rotation, and no relationship was found between other motion functional scores. The study demonstrated that, the use of the pattern of development and motivation of patients to participate is also important among range of motion and muscle strength for upper extremity function.
\end{abstract}

Keywords: Brachial Plexus, Upper Extremity, Range of Motion

\section{Background}

Obstetric brachial plexus palsy (OBPP) refers to upper limb paralysis secondary to a sustained traction or compression injury to the brachial plexus during birth. The reported incidence in developed countries is 2 per 1000 live births (1). Risk factors for OBPP include shoulder dystocia, high gestational age, forceps delivery, and clavicle fracture. The shoulder dystocia has been identified as the greatest risk factor (2). Although 96\% recover spontaneously, a subset of individuals demonstrate persistent neurological and functional deficits due to muscle weakness, soft tissue contractures, and structural deformities.

The assessment and planning of appropriate treatment is important in the early stages of OBPP. Conservative and surgical treatment approaches are not alternative, but complementary to each other. Conservative and surgical treatments both aim to improve the functional level of the organ.

Modified Hoffman technique is used to increase shoulder abduction and external rotation in children with OBPP. After this surgery technique, despite that patients have increased abduction and external rotation, they do not prefer to use the upper limb in their daily living activities (3).

\section{Objectives}

The aim of our study was to examine the relationship between the range of motion and upper extremity function of the shoulder in patients with OBPP who were treated with tendon transfer.

\section{Methods}

A total of 57 patients with OBPP were invited for this cross sectional study. Five patients refused to participate in the study. Four assessments were incomplete and were omitted. Therefore, the study completed with 48 patients (20 girls and 28 boys).

The mean age was $6.1 \pm 1.4$ years and birth weight 4210 $\pm 496.91 \mathrm{~kg}$. In 26 patients right side was involved and 22 patients had left side involvement. In 17 (35.4\%) patients the palsy was of C5-6 type, in 30 (62.5\%) patients of C5-7, and in $1(2.1 \%)$ patient of $\mathrm{C} 5$-T1.

Children 4 - 8 years of age had underwent an operation useing Modified Hoffer Tecnnigue at least 6 month ago. This technique is used to increase shoulder abduction and external rotation with latissimus dorsi and teres major transfers to strengthen external rotation combined with 
subscapularis lengthening, reduction of posterior dislocation or subluxation, and humeral osteotomy, if necessary (3-5).

\subsection{Assessment}

\subsubsection{Demographic Characteristics}

The medical history of the patients was collected via a demographic form prepaired by us. The form included; patient's name and surname, age, gender, type of delivery, birth weight, dominant side of injury, accompanying injuries.

\subsection{Range of Motion}

Range of motion measurements were performed by using a universal goniometer. Shoulder abduction and flexion measurements were performed on standing to avoid compensatory movements and to be able to observe the spine. Shoulder external and internal rotation movements were performed lying prone to be able to stabilize the scapula. Other ROM measurements were performed using standard techniques. First measurements were shown on unaffected side to the patient and then performed on the affected extremity. Measuremented followed KendallMc Creary criterias. Each measurement was repeated three times and average value recorded (6).

\subsection{Mallet Classification}

The modified Mallet classification was utilized to categorize global shoulder function. Patients were asked to perform actively five different shoulder movements: abduction, external rotation, placing the hand behind the neck, placing the hand as high as possible on the spine, and placing the hand to the mouth. Each shoulder movement was subsequently graded on a scale of I (no movement) to $\mathrm{V}$ (normal motion symmetric to the contralateral, unaffected side) (Figure 1) (7). Gross function evaluation was preferred because muscle testing and sensory assessments are not suitable for children and infants. Mallet classification system and modifications are frequently used. This system provides us to follow the results of microsurgery and revision surgery results in obstetric brachial plexus palsy in literature (8).

\subsection{Pediatric Evaluation of Disability Inventory (PEDI)}

PEDI is used to evaluate functional abilities. PEDI consists of 3 parts which are functional skills, caregiver assistance and modifications. Functional skills is a measure of the functional capacity of the child. Functional ability scale contains 197 items. Self-care, mobility and social functions are sub-titles of the scale. Each item is scored as 0 or 1(9).

\subsection{Canadian Occupational Performance Measure (COPM)}

COPM is a tool that determines a person's role in the problems faced in the performance. It is used to measure performance of the patient during an activity with a satisfaction score given by the patient. In the first step the family is asked to determine the difficulties of the child's daily living activities. In the second step parents are asked to score these activities according a Likert scale between 0 and $10(0=$ not important, $10=$ very important $)$. In the third step the family and child are asked to determine the 5 most important activities for the child and score them by Likert scale between 0 and 10 for each activity. Thus, performance and satisfaction scores for children's activities are identified by parents. The last score is calculated by dividing the total performace and satisfaction scores by the number of activities (10-12).

\subsection{Statistical Analysis}

Statistical analysis were performed by using the SPSS software package (version 21.0; SPSS, Inc., Chicago, IL, USA) for Windows. We performed a power analysis to determine the sample size at the beginning of the study. Before the statistical analysis, Kolmogorov-Smirnov test was used to test for normal distribution of data. Descriptive statistics were used to determine differences of subjects' demographic and clinical features. Intercorrelations between parameters were computed with Pearson's correlation analysis. A correlation coefficient between 0.26 and 0.49 reflects poor agreement, those between 0.50 and 0.69 reflect moderate agreement, and those $\geq 0.70$ reflect high agreement. P values $<0.05$ were considered as statistically significant.

\section{Results}

The mean and range of motions are presented in Table 1. The results of Mallet, PEDI and COPM are shown in Table 2. The relationship between range of motion and upper extremity function is presented in Table 3.

When examining relationships between range of motion and functional scores, the only statistically significant relationship existed between COPMP score and external rotation $(r=-0.31 \mathrm{P}=0.04)$. There was no other significant relationship between movements and functional scores (Table 3).

\section{Discussion}

We investigated the relationship between upper extremity functions and shoulder range of motion after shoulder tendon transfer in children with brachial plexus. 


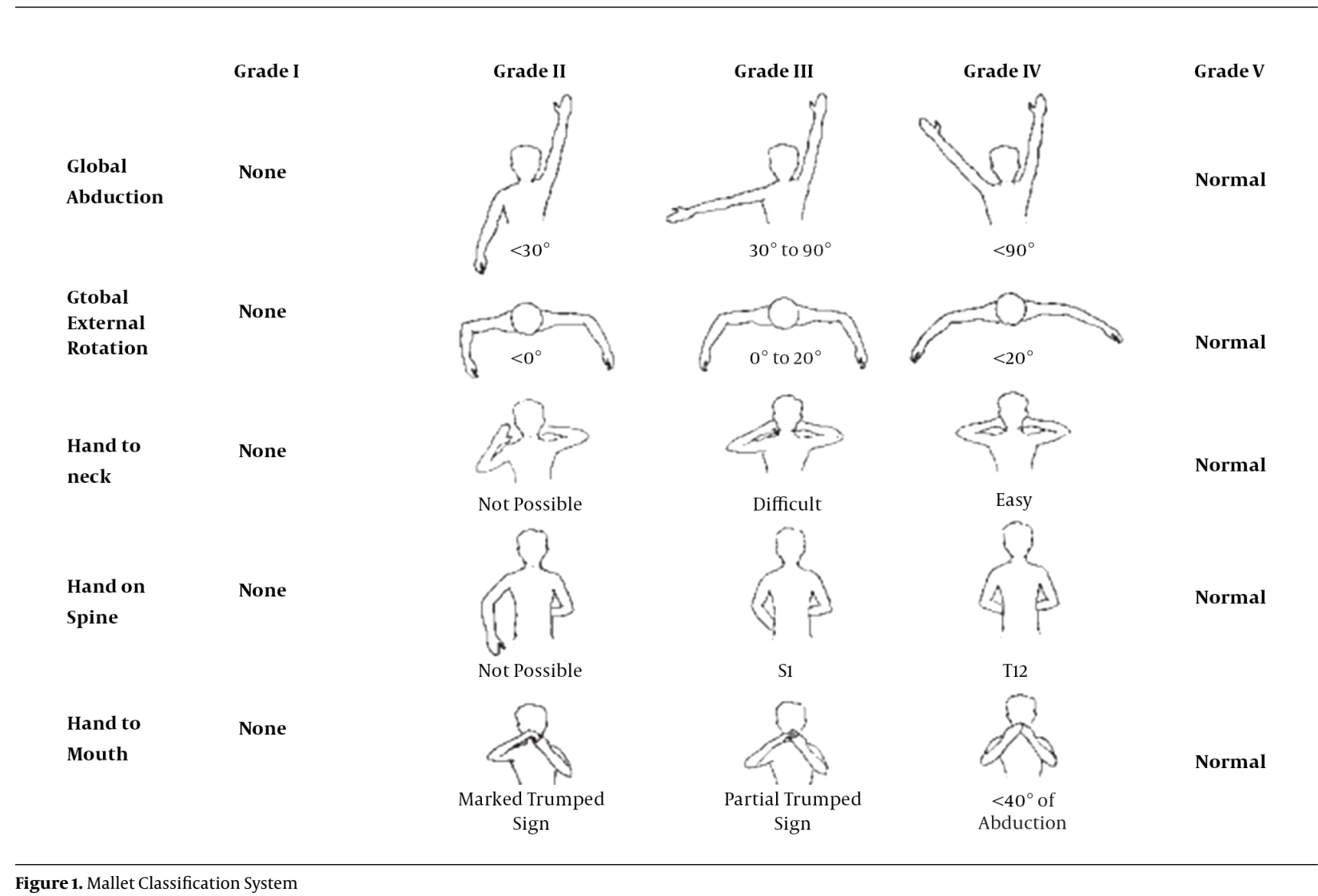

Table 1. Shoulder Movements of Patinets

\begin{tabular}{lcc}
\hline & $\mathbf{X} \pm \mathbf{S D},{ }^{\circ}$ & Min-Max \\
\hline Abduction & $139.89 \pm 23.50$ & $80-180$ \\
Flexion & $137.39 \pm 24.53$ & $80-180$ \\
\hline External Rotation & $74.16 \pm 13.50$ & $50-95$ \\
\hline Internal Rotation & $5.20 \pm 19.07$ & $-20-70$ \\
\hline
\end{tabular}

Table 2. Functional Scores of Patients

\begin{tabular}{lcc}
\hline & $\mathbf{X} \pm \mathbf{S D}$ & Min-Max \\
\hline Mallet & $17.56 \pm 1.14$ & $14-20$ \\
PEDI & $186.66 \pm 10.87$ & $137-197$ \\
COPMP & $5.05 \pm 2.30$ & $0.6-10$ \\
COPMM & $5.43 \pm 3.12$ & $0-10$ \\
\hline
\end{tabular}

We found statistically significant differences between the shoulder abduction of Mallet scales, shoulder abduction, flexion and internal rotation of PEDI, shoulder external and internal rotation of COPMP, and shoulder external ro- tation of COMPS.

The limitation of participation in the activity of upper extremity with obstetric brachial plexus palsy is the main problem $(13,14)$. The aim of all treatments of the issue is to improve functional levels, although in the literature there are few studies on function of upper extremity.

The range of motion measurement is important for patients with OBPP. Surgery increases range of motion $(6,15$, 16). Dedini et al. assessed the range of motion and the amount of using upper extremity in daily life after first year of shoulder tendon transfer. They found a strong correlation between the increase in shoulder abduction and external rotation as well as the amount of using the extremity in daily living activities (15).

Functional tests are used to evaluate efficiance of rehabilitation in children with DBBP. Mallet scale assesses shoulder functions and general movement patterns. It has been used to determine efficacy of both surgical and conservative treatment methods. We believe there is need for studies to evaluate functions related to shoulder abduction.

PEDI has been found to be psycometric because it evaluates activity understoodand participation. Self care sub- 


\begin{tabular}{|c|c|c|c|c|c|c|c|c|c|}
\hline & Mallet & Shoulder abd & Shoulder flek & ER & IR & PEDI & СомРP & COMPS & \\
\hline \multirow[b]{2}{*}{ Mallet } & Pearson Correlation & 1 & $0.314^{\mathrm{a}}$ & 0.257 & 0.065 & 0.184 & $0.409^{\mathrm{b}}$ & 0.282 & 0.193 \\
\hline & Sig. (2-tailed) & & 0.030 & 0.077 & 0.659 & 0.210 & 0.004 & 0.052 & 0.189 \\
\hline \multirow{3}{*}{ Shoulder abd } & Pearson Correlation & $0.314^{\mathrm{a}}$ & 1 & $0.879^{\mathrm{b}}$ & -0.116 & $0.453^{\mathrm{b}}$ & $0.579^{\mathrm{b}}$ & 0.199 & -0.009 \\
\hline & Sig. (2-tailed) & 0.030 & & 0.000 & 0.433 & 0.001 & 0.000 & 0.174 & 0.949 \\
\hline & $\mathrm{n}$ & 48 & 48 & 48 & 48 & 48 & 48 & 48 & 48 \\
\hline \multirow{3}{*}{ Shoulder flek } & Pearson Correlation & 0.257 & $0.879^{\mathrm{b}}$ & 1 & -0.013 & $0.493^{\mathrm{b}}$ & $0.410^{\mathrm{b}}$ & 0.116 & -0.055 \\
\hline & Sig. (2-tailed) & 0.077 & 0.000 & & 0.930 & 0.000 & 0.004 & 0.433 & 0.713 \\
\hline & $\mathrm{n}$ & 48 & 48 & 48 & 48 & 48 & 48 & 48 & 48 \\
\hline \multirow{3}{*}{ ER } & Pearson Correlation & 0.065 & -0.116 & -0.013 & 1 & -0.086 & -0.101 & $-0.412^{\mathrm{b}}$ & $-0.372^{b}$ \\
\hline & Sig. (2-tailed) & 0.659 & 0.433 & 0.930 & & 0.561 & 0.494 & 0.004 & 0.009 \\
\hline & $\mathrm{n}$ & 48 & 48 & 48 & 48 & 48 & 48 & 48 & 48 \\
\hline \multirow{2}{*}{ IR } & Pearson Correlation & 0.184 & $0.453^{\mathrm{b}}$ & $0.493^{\mathrm{b}}$ & -0.086 & 1 & $0.394^{\mathrm{b}}$ & $0.334^{\mathrm{a}}$ & 0.185 \\
\hline & $\mathrm{n}$ & 48 & 48 & 48 & 48 & 48 & 48 & 48 & 48 \\
\hline \multirow{3}{*}{ PEDI } & Pearson Correlation & $0.409^{\mathrm{b}}$ & $0.579^{\mathrm{b}}$ & $0.410^{\mathrm{b}}$ & -0.101 & $0.394^{\mathrm{b}}$ & 1 & $0.447^{\mathrm{b}}$ & $0.343^{\mathrm{a}}$ \\
\hline & Sig. (2-tailed) & 0.004 & 0.000 & 0.004 & 0.494 & 0.006 & & 0.001 & 0.017 \\
\hline & $\mathrm{n}$ & 48 & 48 & 48 & 48 & 48 & 48 & 48 & 48 \\
\hline \multirow{3}{*}{ СОМРP } & Pearson Correlation & 0.282 & 0.199 & 0.116 & $-0.412^{\mathrm{b}}$ & $0.334^{\mathrm{a}}$ & $0.447^{\mathrm{b}}$ & 1 & $0.868^{b}$ \\
\hline & Sig. (2-tailed) & 0.052 & 0.174 & 0.433 & 0.004 & 0.020 & 0.001 & & 0.000 \\
\hline & $\mathrm{n}$ & 48 & 48 & 48 & 48 & 48 & 48 & 48 & 48 \\
\hline \multirow{3}{*}{ COMPS } & Pearson Correlation & 0.193 & -0.009 & -0.055 & $-0.372^{\mathrm{b}}$ & 0.185 & $0.343^{\mathrm{a}}$ & $0.868^{b}$ & 1 \\
\hline & Sig. (2-tailed) & 0.189 & 0.949 & 0.713 & 0.009 & 0.209 & 0.017 & 0.000 & \\
\hline & $\mathrm{n}$ & 48 & 48 & 48 & 48 & 48 & 48 & 48 & 48 \\
\hline
\end{tabular}

${ }^{\mathrm{a}}$ Correlation is significant at the 0.05 level (2-tailed).

$\mathrm{b}$ Correlation is significant at the 0.01 level (2-tailed).

title can be applied alone because mobility and social functions are not affected in children with $\operatorname{OBPP}(9,17)$. PEDI has disadvantages due to only interested in the task has been acomplished or not, and it doesnt evaluate the quality of the performance. PEDI can be used to evaluate the relationship between self care and actitivities related to shoulder abduction, flexion, and internal rotation.

COPM has been used to evaluate functionality within pediatric rehabilitation field. COPM is rarely used in Turkey even for research, yet its use has been the standard tool in clinical practice in various countries. This is the reason we used it in our study. COPM can be used to assess play and self care activities in children. It is recommended to perform the assessment in children younger than 8 years of age by the family. We performed the assessment of children 4-8 years old with their families in our study. There is only one study with children that used COPM in Turkey. Bumin et al. found significant relationship between COPM and PEDI scores, and report that COPM is a valid instrument in children with develepomental disorders (12). We found a significant relationship between COMPP scores and shoulder abduction, external and internal rotation movements; we think that it is related to bathing and dressing activities communicated by the families. There is also a significant relationship between COMPS scores and shoulder external rotation.

We found a correlation between Mallet, PEDI and COPM scores. There is a relationship between different parameters of functional tests and range of motion.

Our study has some limitations. It was a single center study, thus it cannot have wide applicability. A multicentered study is required for more reliable results, even though the assessments completed by one physiotherapist increase the reliability of the use of instrument. In addition, there were no healthy controls to compare.

We believe that upper extremity functions are not only related to muscle strenght and range of motion, they are also needed for the pattern of developement and motivation of the patient for participating in rehabilitation process.

Istanbul faculty of medicine clinical research ethics committee, dated 23.12.2011, No. 08 meeting of the 2011/2103-891 with the number of files received approval and were conducted in accordance with the Declaration of Helsinki. 


\section{References}

1. Rudge WB, Sewell MD, Al-Hadithy N, Wallace CN, Lambert SM Shoulder linked arthroplasty in patients with obstetric brachial plexus palsy can improve quality of life and function at shortterm follow-up. J Shoulder Elbow Surg. 2015;24(9):1473-80. doi: 10.1016/j.jse.2015.03.006. [PubMed: 25958212].

2. Smith EC, Xixis KI, Grant GA, Grant SA. Assessment of obstetric brachial plexus injury with preoperative ultrasound. Muscle Nerve. 2016;53(6):946-50.

3. Murabit A, Gnarra M, O'Grady K, Morhart M, Olson JL. Functional outcome after the Hoffer procedure. Plast Reconstr Surg. 2013;131(6):13006. doi: 10.1097/PRS.0b013e31828b7e0a. [PubMed: 23714791].

4. Boome R. Commentary on Sibinski et al. Management strategies for shoulder reconstruction in obstetric brachial plexus injury with special reference to loss of internal rotation after surgery.J Hand Surg Eur Vol. 2012;37(8):780. doi: 10.1177/1753193412460137. [PubMed: 23042775].

5. Sibinski M, Hems TE, Sherlock DA. Management strategies for shoulder reconstruction in obstetric brachial plexus injury with special reference to loss of internal rotation after surgery. J Hand Surg Eur Vol 2012;37(8):772-9. doi: 10.1177/1753193412440221. [PubMed: 22496183].

6. Ozkan T, Aydin A, Onel D, Ozkan S. [Reconstruction of shoulder abduction and external rotation in obstetric brachial plexus palsy]. Acta Orthop Traumatol Turc. 2004;38(3):161-9. [PubMed: 15347915].

7. Mallet J. [Obstetrical paralysis of the brachial plexus. 3. Conclusions] Rev Chir Orthop Reparatrice Appar Mot. 1972;58:Suppl 1:201-4. [PubMed: 4263993].

8. Gilbert A, Tassin JL. [Surgical repair of the brachial plexus in obstetric paralysis]. Chirurgie. 1984;110(1):70-5. [PubMed: 6734350].

9. Ho ES, Curtis CG, Clarke HM. Pediatric Evaluation of Disability Inventory: its application to children with obstetric brachial plexus palsy.
J Hand Surg Am. 2006;31(2):197-202. doi: 10.1016/j.jhsa.2005.10.007. [PubMed: 16473678].

10. Law M, Baptiste S, Carswell A. Canadian Occupational Performance Measure, Using the COPM. Ottawa: COAT Publications; 2005.

11. Wallen MA, Ziviani JM. Canadian Occupational Performance Measure: impact of blinded parent-proxy ratings on outcome. Can J Occup Ther. 2012;79(1):7-14. doi: 10.2182/cjot.2012.79.1.2. [PubMed: 22439287].

12. Bumin G, Zarif MH, Kayihan H. CPPO22 The effects of cognitive problems on disability and occupational performance in children with developmental disorders in Turkey. EurJPaediatr Neurol. 2007;11:50. doi: 10.1016/s1090-3798(08)70434-3.

13. Strömbeck C, Krumlinde-Sundholm L, Remahl S, Sejersen T. Longterm follow-up of children with obstetric brachial plexus palsy I: functional aspects. Dev Med Child Neurol. 2007;49(3):198-203. doi: 10.1111/j.1469-8749.2007.00198.x.

14. Strombeck C, Remahl S, Krumlinde-Sundholm L, Sejersen T. Longterm follow-up of children with obstetric brachial plexus palsy II: neurophysiological aspects. Dev Med Child Neurol. 2007;49(3):204-9. doi: 10.1111/j.1469-8749.2007.00204.x. [PubMed: 17355477].

15. Dedini RD, Bagley AM, Molitor F, James MA. Comparison of pediatric outcomes data collection instrument scores and range of motion before and after shoulder tendon transfers for children with brachial plexus birth palsy. J Pediatr Orthop. 2008;28(2):259-64. doi: 10.1097/BPO.0b013e3181652135. [PubMed: 18388726].

16. Waters PM, Bae DS. The early effects of tendon transfers and open capsulorrhaphy on glenohumeral deformity in brachial plexus birth palsy. Surgical technique. J Bone Joint Surg Am. 2009;91 Suppl 2:213-22. doi: 10.2106/JBJS.I.00501. [PubMed:19805585].

17. Erkin G, Elhan AH, Aybay C, Sirzai H, Ozel S. Validity and reliability of the Turkish translation of the Pediatric Evaluation of Disability Inventory (PEDI). Disabil Rehabil. 2007;29(16):1271-9. doi: 10.1080/09638280600964307. [PubMed:17654002]. 